\title{
SOCIAL MEDIA AND THE STOCK MARKETS: AN EMERGING MARKET PERSPECTIVE
}

\author{
Shweta AGARWAL (D), Shailendra KUMAR, Utkarsh GOEL \\ Department of Management Studies, Indian Institute of Information Technology, Allahabad, India
}

Received 24 September 2020; accepted 12 May 2021

\begin{abstract}
There are numerous studies that examine the impact of social media on the stock market performance but there is a paucity of such evidences from the emerging economies. Today many multinational banks and other financial conglomerates from the developed countries are expanding their operations to the emerging markets, known for their rapid growth. The businesses in developed countries prefer using social media to reach out to their stakeholders. This might be a challenge as emerging markets are very different from the developed markets in terms of infrastructure and stock market development. This study performs the sentiment analysis of the tweets about the Indian companies that are a part of Nifty50 or any sectorial index, for a period of 15 months. The results from the Granger-causalty tests indicate that the Twitter sentiments have a significant relationship with the indices related to the banking and financial sectors of the Indian stock markets. Results from the Impulse Response Function reveal that, on the index returns, the impact of the negative sentiments stays for a longer period of time than the positive sentiments. This study would help businesses use social media effectively for information sharing and dissemination in the new environment.
\end{abstract}

Keywords: emerging economies, sentiment analysis, social media, Twitter, Indian stock markets, market efficiency, impulse response.

JEL Classification: G140, G10, M21, G41.

\section{Introduction}

Today people are increasingly choosing various online news channels, blogs, virtual communities, and social media networking websites such as Facebook, Twitter, etc., to keep themselves updated about major events around the world as well as to express their emotions/ opinions on various issues (Kapoor et al., 2017). The vast amount of data available on the internet is being used by businesses in order to improve their understanding of their stakeholders and manage risks (Lahey, 2016). This huge amount of information available on the internet has attracted the attention of researchers in myriad ways, e.g. researchers have

\footnotetext{
${ }^{\star}$ Corresponding author. E-mail: me.sshwetaagarwal@gmail.com
} 
analyzed the use of social media data by the startups (Kim \& Choi, 2019), for examining the role of social media in enhancing the collaborative initiatives in temporary project organizations (Rimkuniene \& Zinkeviciute, 2014), its applications in formulating marketing strategies (Ahmed et al., 2017; Klepek \& Starzyczná, 2018), etc.

Social media has now become an extremely popular communication channel as it is easy to share information over social media. The researchers have studied various social media platforms such as Facebook (Siganos et al., 2014), yahoo messenger (Antweiler \& Frank, 2004), StockTwits (Oliveira et al., 2016), etc., for investigating their impact on the stock markets. Twitter has been chosen for this study as it is a favored social media platform for sharing financial information, and the Twitter based trading systems have also been popular among investors (Sprenger et al., 2014). There have been plenty of evidences to suggest that the public sentiments expressed on Twitter have significant predictive power over the performance of the stock market indicators (e.g. He et al., 2016; Liu et al., 2015; Risius et al., 2015). However, the researchers in this area have mostly explored the developed markets, whereas the developing economies' markets are yet to be fully explored in light of the information diffusion through the social media (Agarwal et al., 2019). The studies on the developing countries have majorly paid attention to test only the weak form market efficiency (e.g. Mobarek \& Fiorante, 2014). Since the degree of the irrationality of the investor behavior and the inefficiency of stock markets is not the same across the countries (Chui et al., 2010), it is imperative to explore the behaviour of stock markets in emerging economies with regards to the information available through the social media. The stock markets of the developing countries are still not fully evolved as compared to the developed countries in stock market development (Claessens \& Yurtoglu, 2013).

Twitter is a popular social media platform with 330 million active users worldwide (Clement, 2019). The information on Twitter has been found to have a huge impact on the financial markets; for example, in 2013, the U.S. markets plunged by almost $1 \%$ within 3 minutes of a false news about the bomb attack on White House from the hacked Twitter handle of Associated Press, resulting in heavy losses (Selyukh, 2013). Twitter is an important social media platform for India. Although Twitter does not officially disclose numbers, Taranjeet Sinha (director, India operations for Twitter), in an interview, revealed that India became the fastest growing market for Twitter (in terms of daily active users) in 2017. India almost grew five times as a market for Twitter than the global average (Chaturvedi, 2017). Furthermore, several evidences suggest that the information on Twitter might have an influence over the Indian investors and the markets, e.g., Security and Exchange Board of India [SEBI] issued a warning to an investment advisor against the use of Twitter for giving advice related to the stock markets to the investors, to protect the interests of the investors (SEBI, 2018). More recently, it was seen that when the Nifty futures trading on the Singapore exchange fell 200 points in reaction to the Iranian missile attack on U.S. troops, the stocks recovered 100 points when the U.S. president's tweet eased down the possibilities of a rise in the US-Iranian tensions (ETMarkets.com, 2020). Also, India's Nifty shares closed 1.58\% higher after the U.S. President's response on Twitter (George, 2020). 
Following are the main contributions of this paper to the existing literature:

a. It gives a comprehensive view of how the information over the Twitter affects the stock markets of a developing country, with evidences from India.

b. It explores, for the first time, according to our knowledge, the impact of Twitter sentiments on the broad market indices as well as the indices of the different sectors of a country's economy.

c. It investigates the impact of positive and negative sentiments on the stock markets (broad market indices and the sectorial indices) of a developing country.

In this study, sentiment analysis of the tweets about the Indian companies that are a part of the National broad market index Nifty50 and the other 11 sectorial indices of the Indian economy has been performed using VADER. It has been specifically attuned to capture the sentiments (expressed through emoticons, acronyms, and abbreviations) in micro-blog like contexts. It also classifies each tweet as positive or negative. The stock market data has been used for the same indices. Various statistical tests are then conducted to find out a relationship between the Twitter sentiments and the stock market indices. The results have been confirmed by using the lexicon based approach for sentiment analysis.

This paper has been organised into 6 sections. Section 1 describes the available literature in the area and highlights the gaps in the existing literature. Section 2 illustrates the data and methodology used for sentiment analysis and the calculations for the stock market indicators used in this paper. Section 3 provides the results of the contemporaneous correlation and Granger Causalty between the Indian stock market indicators and the Twitter sentiments. Section 4 provides further details of the Twitter information has an impact Impulse Response Function used for the empirical analysis and describes how the on the obtained results. Section 5 tests the robustness of the sentiment analysis process and the results. Section 6 discusses the findings of the paper with practical implications and suggestions for future research. Last Section concludes the present study.

\section{Literature review}

The Efficient Market hypothesis states that the stock prices already fully reflect all the relevant market information and therefore cannot be predicted (Fama, 1965). However this theory was revised and on the basis of the "relevant information" that should be reflected in the market prices of a stock, three levels of market efficiency were introduced, weak form efficiency (the changes in historical price and volume), semi strong form efficiency (all the publicly available information) and the strong form efficiency (all the relevant public as well as private information) (Malkiel \& Fama, 1970).

In this era of Big Data, prediction of stock prices using information available on the social media has been widely studied. Many researchers have investigated the role of Twitter information in the financial markets (e.g. Bollen et al., 2011; Tetlock, 2007). Zheludev et al. (2014) extracted positive and negative emotions from the Twitter and demonstrate that it can significantly predict the future prices of the S\&P500 index. Research has shown that the negative emotions as expressed on Twitter have a significant impact on the firm-specific stock prices (He et al., 2016; Risius et al., 2015). Liu et al. (2015) identified homogenous groups 
of firms with stock co-movements using Twitter based metrics like number of tweets, followers, etc. Daily happiness index (constructed by the sentiment analysis of the $10 \%$ of all the Twitter messages) has been widely used to study the impact of the social media on the financial markets. Zhang et al. (2016) observed that the online sentiments from Twitter happiness index have significant predictive power over the stock market performance indicators (index returns and range-based volatility) of the 11 developed countries. You et al. (2017) investigated the relationship between the stock markets of 10 developed countries and Twitter happiness index. The authors found that the stocks with higher returns get more influenced by the investor sentiments than the stocks with lower returns. More recently, Zhang et al. (2018) examined the impact of Twitter sentiments on the index returns of 40 countries from 4 regions: America, Europe, Asia Pacific, and Middle East and North Africa. They observed interdependencies between the online activities on Twitter and the stock market performance. Leitch and Sherif (2017) constructed a Twitter sentiment score to forecast stock returns for the firms. Many recent researches have also established that the user generated content on the social media has a significant influence on the movements in the stock markets (Fan et al., 2020a, 2020b; van Dieijen et al., 2020).

However, it has been observed that most of this research is concentrated on the markets of the developed countries (Agarwal et al., 2019). The influence of the Twitter information on the markets of the emerging economies needs to be explored, as the irrationality of the investor behavior and the degree of inefficiency of stock markets differs across the countries (Chang \& Lin, 2015). There is still exiguous literature available till now to help understand and quantify the impact of the Twitter sentiments on the Indian Stock Markets (e.g. Kaushik et al., 2017). Moreover, most of the studies in the area have examined the impact of social media content on the stock market performance of a country using the national indices or have studied the influence on the performance of some individual listed companies; but the impact of the social media on the indices of the various sectors of the economy of a country is yet to be explored. It has been observed that the rate of social media adoption varies across the industries, e.g. I.T. industry is among the pioneers in adopting the social media whereas the Energy, Metals, and mining sectors being the laggards in this respect (Culnan et al., 2010).

According to the World Federation of Exchanges (WFE), the National Stock Exchange (NSE), India is the second largest in the world by equity trading volume in 2018 (National Stock Exchange [NSE], 2019). Bhardwaj et al. (2015) demonstrated techniques that can be used for sentiment analysis for the live server data from the Indian stock exchanges. However, none of the techniques were implemented by them. In an event study, tweets were collected around a major event in the Indian economy - Demonetization, to find whether the public sentiments expressed on Twitter influence the movements of the Indian stock markets (Mohan \& Kar, 2017), but no significant relationship was found. Nayak et al. (2016) attempted to forecast the Indian stock markets using the twitter sentiment, using machine learning technique - Support Vector Machine. But they did not discuss the statistical significance of their results. None of the studies so far have compared the influence of negative and positive public sentiments as expressed on the Twitter, on the Indian equity markets. A few more studies have suggested that information from the internet does not have any 
significant predictive power over investor sentiments e.g. Kim \& Kim (2014). They used the messages posted on the yahoo finance message board. The sentiment of the messages used in this study was among the five categories "Strong Buy", "Buy", "Hold", "Strong Sell" and "Sell" that is explicitly provided by the message board to the retail investors.

This study seeks to answer the research question: How does the information over Twitter influence the Indian stock markets? For this, the following hypothesis are proposed as shown in Table 1.

Table 1. Table of hypotheses

\begin{tabular}{|c|c|}
\hline $\mathrm{H}_{1}$ & There is no relation between returns of NIFTY 50 and positive Twitter Sentiment. \\
\hline $\mathrm{H}_{2}$ & There is no relation between returns of index Nifty Auto and positive Twitter Sentiment. \\
\hline $\mathrm{H}_{3}$ & $\begin{array}{l}\text { There is no relation between returns of index Nifty Pharma and positive Twitter } \\
\text { Sentiment. }\end{array}$ \\
\hline $\mathrm{H}_{4}$ & There is no relation between returns of index Nifty Bank and positive Twitter Sentiment. \\
\hline $\mathrm{H}_{5}$ & $\begin{array}{l}\text { There is no relation between returns of index Nifty PSU Bank and positive Twitter } \\
\text { Sentiment. }\end{array}$ \\
\hline $\mathrm{H}_{6}$ & $\begin{array}{l}\text { There is no relation between returns of index Nifty Private Bank and positive Twitter } \\
\text { Sentiment. }\end{array}$ \\
\hline $\mathrm{H}_{7}$ & There is no relation between returns of index Nifty Realty and positive Twitter Sentiment. \\
\hline $\mathrm{H}_{8}$ & There is no relation between returns of index Nifty FMCG and positive Twitter Sentiment. \\
\hline $\mathrm{H}_{9}$ & $\begin{array}{l}\text { There is no relation between the returns of index Nifty Media and positive Twitter } \\
\text { Sentiment. }\end{array}$ \\
\hline $\mathrm{H}_{10}$ & $\begin{array}{l}\text { There is no relation between the returns of index Nifty Metals and positive Twitter } \\
\text { Sentiment. }\end{array}$ \\
\hline $\mathrm{H}_{11}$ & There is no relation between the returns of index Nifty IT and positive Twitter Sentiment. \\
\hline $\mathrm{H}_{12}$ & $\begin{array}{l}\text { There is no relation between the returns of index Nifty Financial Services and positive } \\
\text { Twitter Sentiment. }\end{array}$ \\
\hline $\mathrm{H}_{13}$ & There is no relation between returns of NIFTY 50 and the negative Twitter Sentiment. \\
\hline $\mathrm{H}_{14}$ & There is no relation between returns of index Nifty Auto and negative Twitter Sentiment. \\
\hline $\mathrm{H}_{15}$ & $\begin{array}{l}\text { There is no relation between returns of index Nifty Pharma and negative Twitter } \\
\text { Sentiment. }\end{array}$ \\
\hline $\mathrm{H}_{16}$ & There is no relation between returns of index Nifty Bank and negative Twitter Sentiment. \\
\hline $\mathrm{H}_{17}$ & $\begin{array}{l}\text { There is no relation between returns of index Nifty PSU Bank and negative Twitter } \\
\text { Sentiment. }\end{array}$ \\
\hline $\mathrm{H}_{18}$ & $\begin{array}{l}\text { There is no relation between returns of index Nifty Private Bank and negative Twitter } \\
\text { Sentiment. }\end{array}$ \\
\hline $\mathrm{H}_{19}$ & There is no relation between returns of index Nifty Realty and negative Twitter Sentiment. \\
\hline $\mathrm{H}_{20}$ & $\begin{array}{l}\text { There is no relation between returns of index Nifty FMCG and negative Twitter } \\
\text { Sentiment. }\end{array}$ \\
\hline $\mathrm{H}_{21}$ & There is no relation between returns of index Nifty Media and negative Twitter Sentiment. \\
\hline $\mathrm{H}_{22}$ & There is no relation between returns of index Nifty Metals and negative Twitter Sentiment. \\
\hline $\mathrm{H}_{23}$ & There is no relation between the returns of index Nifty IT and negative Twitter Sentiment. \\
\hline $\mathrm{H}_{24}$ & $\begin{array}{l}\text { here is no relation between the returns of index Nifty Financial Services and negative } \\
\text { Twitter Sentiment. }\end{array}$ \\
\hline
\end{tabular}




\section{Data and methodology}

This paper investigates relationship between the information on the Twitter and the Indian stock markets. This study extracts two different kind of information from the twitter: a) optimistic public sentiments, b) pessimistic public sentiments. The daily Twitter data and the stock market data has been collected for the period of 15 months (i.e. 1, Aug 2017 to 10, Nov 2018).

\subsection{Collection of social media data}

The Twitter API has not been used because it has been criticized for being restricted by Twitter to sourcing tweets in last 8-9 days only from the search date (Leitch \& Sherif, 2017). Therefore, a bespoke code was written specifically for this study to extract data from Twitter, using Python. Only the tweets about the companies (144) that are a part of the Nifty50 or the 11 sectorial indices of the Indian economy (Nifty Realty, Nifty Auto, Nifty Bank, Nifty Pharma, Nifty PSU Bank, Nifty Financial Services, Nifty Private Bank, Nifty FMCG, Nifty Metals, Nifty Media, Nifty IT), have been considered. Approximately 16.4 million Twitter tweets were collected for the study. The keyword search (mentions, twitter handles, stock symbols and the company names) is used for data collection.

\subsection{Collection of stock market data}

The daily stock market data is collected from the NSE website (NSE, 2019). All the market indices are rebalanced semi-annually and additional reconstitution of the indices also takes place in case any of the constituent companies undergoes a scheme of arrangement for corporate events such as merger, suspension, spin-off, etc. The Twitter data as well as the stock market data has been collected carefully, taking care of all the inclusions/exclusions done in the indices during the sample period.

Twitter platform has been specifically chosen for this study and the other popular online sources of social media information have not been included, e.g. Facebook, Snapchat, and Instagram, because of three reasons. Firstly, it is not possible to extract data from the Facebook due to the restrictions after the Cambridge Analytica Scandal in early 2018 (Gonzalez, 2018). Secondly, earlier research has found evidences to suggest that while the sentiments expressed on the Facebook/Twitter/stock message boards can influence the financial decisions, in contrast to the Snapchat and Instagram that are used by people primarily for entertainment, following fashion and sharing personal content (Phua et al., 2017)this study examined consumers' use of one of four social networking sites (SNSs. Other specialized social networks in financial markets such as StockTwits or Scutify have not been used in this study as the Indian companies/markets do not have any presence on these networks.

The market indicators examined in this research are: Open-to-close returns and rangebased volatility. There are a few reasons for choosing these variables. The Open-to-close returns are chosen for the study instead of Close-to-close returns because they suffer from non-trading day gaps (when trading is closed due to weekends and holidays). The investors might consider cashing out their assets in the holiday period and re-enter the market on the 
next trading day. Also, it has been observed that the traders are more active in the beginning and end of the week as compared to the mid-week. This makes close-to-close returns suffer from seasonality patterns ( $\mathrm{Li}$ et al., 2014). Similarly, the range based volatility measures are found to be highly efficient and more robust than the returns based volatility measures (Díaz-Mendoza \& Pardo, 2019; Garman \& Klass, 2002). Researchers have observed that the in-sample models that incorporate non-trading days period effects, using GARCH models do not show any increase in the forecasting ability in comparison to the models that do not allow for these effects (Hansson \& Hördahl, 2005). Following these researchers, the variables used in this study have been defined as follows.

$$
\begin{gathered}
\operatorname{Ret}_{p, q}=\ln \frac{\text { Close }_{p, q}}{\operatorname{Open}_{p, q}} ; \\
R v_{i, j}=\frac{1}{2} h l_{i, j}^{2}-\left(2 \ln ^{2}-1\right) o c_{i, j}^{2},
\end{gathered}
$$

where Ret $_{i, j}$ denotes Open-to-Close returns on any trading day $p$ for index $q$. Close $_{p, q}$ and Open $_{p, q}$ are the closing and opening prices on trading day $p$ for index $q . R v_{i, j}$ represents the volatility (range-based) on any trading day $i$ for index $j, h l_{i, j}^{2}$ is the difference in natural logarithms of the highest and lowest prices on trading day $i$ for index $j$ and $o c_{i, j}^{2}$ is the difference in natural logarithms of the opening and closing prices on trading day $i$ for index $j$.

\subsection{Sentiment analysis}

The sentiment analysis of the Twitter messages is done using VADER - a parsimonious rule based, human validated sentiment analysis method. VADER has been found to outperform individual human raters in assessing the sentiments of the tweets and also generalizes more favorably across contexts than any other tools i.e. LIWC, ANEW, the General Inquirer, SentiWordNet and other machine learning oriented approaches such as Naïve Bayes algorithm, SVM, etc. (Hutto \& Gilbert, 2014). Its sentiment intensity scores, also known as valence scores have been rated by the human raters. For example, the words like "good" has a positive intensity score of 1.9 whereas the word "great" has a score of 3.1. This results in two scores of interest: positive sentiment score and the negative sentiment score. To assess the overall sentiment of the text, a compound sentiment score is then calculated by weighting each word in the social media message/post by the five rules that alter the sentiment intensity of the word (due to negation, emoticons, exclamation marks, etc.) and then normalizes (between -1 to +1 ) the sum of valence scores for each word in the lexicon. The compound score is then compared to a threshold value ( 0.5 , as recommended by the VADER's creators) for classification as either positive or negative.

Since the VADER does not require a training data and is constructed using domain independent lexicon rated by the human raters. It has been used by researchers for the sentiment analysis of the social media texts in a variety of disciplines, e.g. online health information (experiences and opinions of the patients regarding the treatments received), (Hart et al., 2020), movie reviews posted online where VADER outperformed other sentiment analyzers 
such as Textblob and NLTK (Kumaresh et al., 2019), product reviews posted by the consumers on the Amazon (Bag et al., 2019), etc. This study uses VADER to compute the daily average positive and negative scores, to represent the daily optimistic and pessimistic public sentiments on the Twitter for each sector, as following:

$$
\begin{gathered}
A v g_{-} \operatorname{Pos}_{i, j}=\frac{\text { Sum_Pos }_{i, j}}{\text { Total_Pos }_{i, j}} ; \\
A v g_{-} \mathrm{Neg}_{i, j}=\frac{\text { Sum_Neg }_{i, j}}{\text { Total_Neg }_{i, j}},
\end{gathered}
$$

where Avg_Pos ${ }_{i, j}\left(A v g_{-} N_{e g} g_{i, j}\right.$ ) represents the optimistic (pessimistic) public sentiment on social media for the economic sector $j$ on day $i, \operatorname{Sum}_{N e g i, j}\left(\operatorname{Sum}_{P o s i, j}\right)$ is the sum of the scores of the social media messages/posts with negative (positive) compund score, for all the constituent companies of the economic sector $j$ on day $i$ and $\operatorname{Total}_{\text {Negi,j }}\left(\right.$ Total $_{P o s i, j}$ ) is the total number of negative (positive) messages/posts on social media for all the constituent companies of the economic sector $j$ on day $i$.

\section{Analysis and results}

\subsection{Contemporaneous correlation}

This section explores the contemporaneous effect of public sentiments as expressed on the Twitter on the Indian equity market indicators. The results of the same have been depicted in Tables 2 and 3.

Table 2. Kendall correlation coefficients between Avg_Pos and Indian Stock market indicators

\begin{tabular}{|l|c|c|}
\hline \multirow{2}{*}{\multicolumn{1}{c|}{ Index }} & \multicolumn{2}{|c|}{ Stock Market Indicators } \\
\cline { 2 - 3 } & Ret & $\mathrm{Rv}$ \\
\hline Nifty Auto & .043 & -.002 \\
\hline NIFTY Bank & -.021 & -.006 \\
\hline NIFTY Financial Services & -.021 & $.192^{\star *}$ \\
\hline NIFTY FMCG & .002 & .048 \\
\hline NIFTY IT & -.031 & .015 \\
\hline NIFTY Media & .026 & .028 \\
\hline NIFTY Metals & -.013 & -.013 \\
\hline NIFTY Pharma & -.064 & .036 \\
\hline NIFTY PSU BANK & -.038 & -.019 \\
\hline NIFTY Pvt Bank & .002 & $.228^{* *}$ \\
\hline NIFTY Realty & -.076 & .028 \\
\hline NIFTY50 & .050 & $.166^{\star *}$ \\
\hline
\end{tabular}


Table 3. Kendall correlation coefficients between Avg_Neg and Indian Stock market indicators

\begin{tabular}{|l|c|c|}
\hline \multirow{2}{*}{\multicolumn{1}{|c|}{ Index }} & \multicolumn{2}{|c|}{ Stock Market Indicators } \\
\cline { 2 - 3 } & Ret & $\mathrm{Rv}$ \\
\hline Nifty Auto & -.058 & .023 \\
\hline NIFTY Bank & -.001 & $.193^{* *}$ \\
\hline NIFTY Financial Services & -.043 & -.024 \\
\hline NIFTY FMCG & -.042 & -.013 \\
\hline NIFTY IT & .037 & .051 \\
\hline NIFTY Media & -.059 & -.033 \\
\hline NIFTY Metals & $-.112^{*}$ & -.008 \\
\hline NIFTY Pharma & .047 & $-.114^{\star}$ \\
\hline NIFTY PSU BANK & .060 & -.037 \\
\hline NIFTY Pvt Bank & $.110^{\star}$ & .017 \\
\hline NIFTY Realty & .082 & -.007 \\
\hline NIFTY50 & -.011 & .026 \\
\hline
\end{tabular}

Table 2 and Table 3 clearly show that the correlation between the returns from the Nifty50 and the Twitter sentiments is insignificant. The returns for the Metals and the Private Banks sector are also found to be correlated to the negative sentiments derived from the Twitter messages. Hence we fail to accept the hypothesis $\mathrm{H}_{18}$ and $\mathrm{H}_{22}$.

\subsection{Lead-lag relationship}

The causal relationship between the positive and negative Twitter sentiments and the Indian stock market indicators (i.e., stock returns and the range based volatility) is examined using the Granger Causalty tests, using the following models (Enders \& Granger, 1998).

$$
\begin{gathered}
P_{t}=u_{P}+\sum_{i=1}^{f} \lambda_{i} P_{t-i}+\sum_{j=1}^{s} \delta_{j} Q_{t-j}+\varepsilon_{t i=1}^{f} ; \\
Q_{t}=u_{Q}+\sum_{i=1}^{f} \lambda_{i} Q_{t-1}+\sum_{j=1}^{s} \delta_{j} P_{t-j}+\varepsilon_{t=1}^{f},
\end{gathered}
$$

where $f$ and $s$ represent the lag length, $P_{t}$ denotes different stock market variables, i.e., stock returns and the range based volatility with respect to the Indian equity markets, $Q_{t}$ denotes the sentiment proxies i.e., Avg_Pos, Avg_Neg, and Pol. $\lambda$ and $\delta$ are the coefficients, $u_{p}$ and $u_{Q}$ are the intercept terms and $\varepsilon_{t}$ is the regression error. $P_{t}$ and $Q_{t}$ confirm the stationarity property (through KPSS and ADF test). The selection of the lag length is based on the Bayesian Information Criteria (BIC) (Siganos et al., 2014). The selected lags for the models in Eq. (5) and Eq. (6) vary across different variables $\left(P_{t}\right.$ and $\left.Q_{t}\right)$. Table 4 and Table 5 show the Granger causality results for Nifty50 and the 11 sectorial indices.

The results from the Granger causality tests show that the public sentiments expressed on social media (both the optimistic and the pessimistic sentiments) can granger-cause the returns of the sectorial indices related to the banking and financial services industry i.e. NIFTY Bank, NIFTY Financial Services, and the NIFTY Private Bank. Hence we fail to accept the hypothesis $\mathrm{H}_{4}, \mathrm{H}_{6}, \mathrm{H}_{12}, \mathrm{H}_{16}, \mathrm{H}_{18}$, and $\mathrm{H}_{24}$. 
Table 4. Table depicts the outcome of the Granger-causality test between the Open-to-close returns and the sentiment indicators Avg_Neg and Avg_Pos. The table displays the F-statistics and the critical values are put in the parenthesis. ${ }^{\star}$ represents the statistical significance at $5 \%$ level

\begin{tabular}{|l|c|c|c|c|}
\hline \multicolumn{1}{|c|}{ Index } & $\begin{array}{c}\text { Null: Avg_Pos } \\
\text { does not cause Ret }\end{array}$ & $\begin{array}{c}\text { Null: Ret does not } \\
\text { cause Avg_Pos }\end{array}$ & $\begin{array}{c}\text { Null: Avg_Neg } \\
\text { does not cause Ret }\end{array}$ & $\begin{array}{c}\text { Null: Ret does not } \\
\text { cause Avg_Neg }\end{array}$ \\
\hline NIFTY Auto & $(3.095) 3.906$ & $(2.0252) 3.906$ & $(0.290) 3.906$ & $(1.2216) 3.906$ \\
\hline NIFTY Bank & $(4.645)^{*} 3.906$ & $(2.0007) 3.906$ & $(5.628)^{*} 3.906$ & $(2.1253) 3.906$ \\
\hline $\begin{array}{l}\text { NIFTY Financial } \\
\text { Services }\end{array}$ & $(4.303)^{\star} 3.906$ & $(0.1333) 3.906$ & $(6.233)^{\star} 3.906$ & $(3.534) 3.906$ \\
\hline NIFTY FMCG & $(3.011) 3.906$ & $(0.4527) 3.906$ & $(1.017) 3.906$ & $(2.1504) 3.906$ \\
\hline NIFTY IT & $(0.1807) 3.906$ & $(0.6324) 3.906$ & $(0.192) 3.906$ & $(1.1083) 3.906$ \\
\hline NIFTY Media & $(5.538)^{*} 3.906$ & $(1.27) 3.906$ & $(2.316) 3.906$ & $(2.6826) 3.906$ \\
\hline NIFTY Metal & $(2.998) 3.906$ & $(1.6235) 3.906$ & $(2.201) 3.906$ & $(1.1670) 3.906$ \\
\hline NIFTY Pharma & $(1.9424) 3.906$ & $(0.1088) 3.906$ & $(1.665) 3.906$ & $(0.3402) 3.906$ \\
\hline NIFTY PSU Bank & $(2.112) 3.906$ & $(0.0948) 3.906$ & $(2.253) 3.906$ & $(5.2236)^{*} 3.906$ \\
\hline NIFTY Private Bank & $(4.721)^{*} 3.906$ & $(0.9989) 3.906$ & $(4.838)^{*} 3.906$ & $(1.786) 3.906$ \\
\hline NIFTY Realty & $(0.787) 3.906$ & $(1.6672) 3.906$ & $(0.880) 3.906$ & $(0.2265) 3.906$ \\
\hline NIFTY 50 & $(2.931) 3.906$ & $(0.6998) 3.906$ & $(1.0680) 3.906$ & $(0.7180) 3.906$ \\
\hline
\end{tabular}

Table 5. The table depicts the outcome from the Granger-causality test between the volatility (Rangebased) and the positive and negative sentiment indicators. The tables shows the F-statistics and values in the paranthesis are the critical. ${ }^{* *}$ represents the statistical significance at $1 \%$ level

\begin{tabular}{|l|c|c|c|c|}
\hline \multicolumn{1}{|c|}{ Index } & $\begin{array}{c}\text { Null: Avg_Pos } \\
\text { does not cause } \\
\text { Range_v }\end{array}$ & $\begin{array}{c}\text { Null: Range_v } \\
\text { does not cause } \\
\text { Avg_Pos }\end{array}$ & $\begin{array}{c}\text { Null: Avg_Neg } \\
\text { does not cause } \\
\text { Range_v }\end{array}$ & $\begin{array}{c}\text { Null: Range_v } \\
\text { does not cause } \\
\text { Avg_Neg }\end{array}$ \\
\hline NIFTY Auto & $(1.544) 3.906$ & $(7.2785)^{\star *} 6.803$ & $(0.303) 3.906$ & $(1.4133) 3.906$ \\
\hline NIFTY Bank & $(0.572) 3.906$ & $(0.3952) 3.906$ & $(0.0614) 3.906$ & $(1.9452) 3.906$ \\
\hline $\begin{array}{l}\text { NIFTY Financial } \\
\text { Services }\end{array}$ & $(0.0085) 3.906$ & $(0.0162) 3.906$ & $(0.00502) 3.906$ & $(3.664) 3.906$ \\
\hline NIFTY FMCG & $(0.258) 3.906$ & $(1.5992) 3.906$ & $(0.283) 3.906$ & $(1.0615) 3.906$ \\
\hline NIFTY IT & $(6.949) 3.906$ & $(0.4421) 3.906$ & $(1.168) 3.906$ & $(0.001) 3.906$ \\
\hline NIFTY Media & $(1.4404) 3.906$ & $(1.3720) 3.906$ & $(0.491) 3.906$ & $(1.6385) 3.906$ \\
\hline NIFTY Metal & $(1.842) 3.906$ & $(1.6222) 3.906$ & $(1.555) 3.906$ & $(2.3322) 3.906$ \\
\hline NIFTY Pharma & $(0.5576) 3.906$ & $(0.1501) 3.906$ & $(2.763) 3.906$ & $(0.4744) 3.906$ \\
\hline NIFTY PSU Bank & $(1.712) 3.906$ & $(0.1833) 3.906$ & $(0.779) 3.906$ & $(2.4894) 3.906$ \\
\hline NIFTY Private Bank & $(0.444) 3.906$ & $(2.6658) 3.906$ & $(0.492) 3.906$ & $(1.852) 3.906$ \\
\hline NIFTY Realty & $(2.172) 3.906$ & $(6.7960) 3.906$ & $(1.629) 3.906$ & $(2.6142) 3.906$ \\
\hline NIFTY 50 & $(0.215) 3.906$ & $(0.0106) 3.906$ & $(0.0910) 3.906$ & $(1.8157) 3.906$ \\
\hline
\end{tabular}




\section{Impulse response}

The Impulse Response Function (IRF) is used to examine the response of a variable to a unit shock (one standard deviation) in another variable. To assess the influence of the Twitter information on the returns from the Indian equity markets, IRFs are computed on the basis of the VAR (Vector Auto Regression) system parameters. Following Deng et al. (2018) IRFs have been used in this study, to perform a detailed sector analysis and look deeper into studying the influence of twitter on the equity markets over time. Following (Trusov et al., 2008), the IRFs are shown graphically so as to get a visual impression of the dynamic interrelationships among the stock market returns and the public sentiment indicators derived from the Twitter for the sectorial indices NIFTY Private Bank, NIFTY Financial services and NIFTY Bank. These sectors are specifically chosen as it is evident from the Table 5 that the optimistic and the pessimistic public sentiments can granger-cause the returns of the sectorial indices related to the banking and financial services industry i.e. NIFTY Bank, NIFTY Financial Services, and the NIFTY Private Bank. Other sectors cannot be analyzed using IRFs because there is no evidence of causalty between their returns and the Twitter information. The results are displayed in Table 6 (Figure 1 to Figure 6). Other sectors cannot be analyzed

Table 6. This table shows the graphical representation of the IRFs applied to dynamic interrelationships among the stock market returns and the public sentiment indicators derived from the Twitter for the sectorial indices NIFTY Private Bank, NIFTY Financial services and NIFTY Bank

\begin{tabular}{|c|c|c|}
\hline 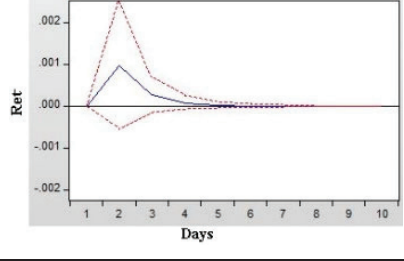 & Days S $^{0}$ & .001- \\
\hline $\begin{array}{l}\text { Figure } 1 \text {. Depicts the response of } \\
\text { Ret to a unit shock in Avg_Pos, } \\
\text { computed for the index NIFTY } \\
\text { Private Bank }\end{array}$ & $\begin{array}{l}\text { Figure } 2 \text {. Depicts the response of } \\
\text { Ret to a unit shock in Avg_Neg, } \\
\text { computed for the index NIFTY } \\
\text { Private Bank }\end{array}$ & $\begin{array}{l}\text { Figure 3. Depicts the response of } \\
\text { Ret to a unit shock in Avg_Pos, } \\
\text { computed for the index NIFTY } \\
\text { Financial services }\end{array}$ \\
\hline (1) & 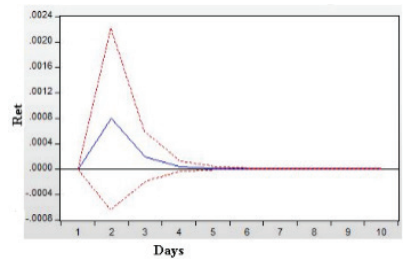 & 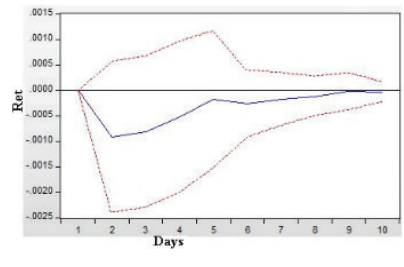 \\
\hline $\begin{array}{l}\text { Figure } 4 \text {. Depicts the response of } \\
\text { Ret to a unit shock in Avg_Neg, } \\
\text { computed for the index NIFTY } \\
\text { Financial Services }\end{array}$ & $\begin{array}{l}\text { Figure 5. Depicts the response of } \\
\text { Ret to a unit shock in Avg_Pos, } \\
\text { computed for the index NIFTY } \\
\text { Bank }\end{array}$ & $\begin{array}{l}\text { Figure } 6 \text {. Depicts the response of } \\
\text { Ret to a unit shock in Avg_Neg, } \\
\text { computed for the index NIFTY } \\
\text { Bank }\end{array}$ \\
\hline
\end{tabular}


using IRFs because there is no evidence of causalty between their returns and the Twitter information.

It is observed in section 4.b. that the movement of the indices related to the banking and financial services sectors is significantly influenced by the public sentiments (either the optimistic or the pessimistic) expressed on the Twitter. The IRFs help in providing a detailed sector analysis. A comparison based on the influence of the positive and the negative sentiments on the returns, is provided in Figure 1 to Figure 6. The sectors NIFTY Private Bank, NIFTY Financial services and NIFTY Bank are chosen for making the comparisons. The stock market returns (Ret) for the sectors and the sentiment indicators (both positive and negative) have been confirmed for the stationarity properties (through the ADF and KPSS test).

Figure 1 and Figure 2 show that the impact of the positive and the negative sentiments on the returns of the NIFTY Private Bank is significantly different from zero only for a period of 3 days and 4 days, respectively. The Figure 3 and Figure 4 suggest that the impact of the positive and the negative sentiments on the returns of the NIFTY Financial services is significant for a period of 6 days and 4 days, respectively. The impact of the positive and the negative sentiments on the returns of the NIFTY Bank is observed for a period of 3 and 8 days respectively, as shown in the Figure 5 and Figure 6.

\section{Robustness of the results}

To check the robustness of our results, a lexicon-based approach has been used for the sentiment analysis. Although this paper does not aim to test and compare the efficiency of the various sentiment analysis algorithms but because the sentiment measures extracted using VADER demonstrate insignificant correlation with the majority of the indices in Indian market and also that VADER is a domain-independent sentiment classifier, hence it becomes imperative to test the results by using another algorithm (specifically designed for the financial domain) for sentiment analysis. Following other researchers (Feldman et al., 2010; Liu \& McConnell, 2013) a finance related lexicon (Loughran \& Mcdonald, 2011) is chosen. This dictionary consists of negative and the positive words referred in business context. For example, the word "capital" is often referred as a negative term but in the context of finance it is a neutral term that does not represent any sentiment. The number of positive and negative words (for the companies belonging to Nifty50 and any of the economic sectors) in the daily tweets, indicates the flow of positive and the negative information. The sentiment analysis (with this approach) is performed using the same sample of 15 months (i.e. 1, Aug 2017 to 10, Nov 2018). Polarity scores for each of the sectors and Nifty50 are computed as:

$$
\operatorname{Pol}_{i, j}=\frac{\operatorname{Pos}_{i, j}-\mathrm{Neg}_{i, j}}{\operatorname{Pos}_{i, j}+N e g_{i, j}},
$$

where, $\mathrm{Pol}_{i, j}$ represents the sentiment polarity score at day i for the Nifty50 and the sector $\mathrm{j}$, and $\mathrm{Neg}_{i, j}\left(\mathrm{Pos}_{i, j}\right)$ is the number of negative (positive) words for the companies constituting Nify50 and the economic sector $j$ at day $i$. 
Kendall correlations, which quantify the contemporaneous effect of the polarity scores on the stock market indicators are calculated for Nifty50 and each of the 11 sectorial indices. Table 7 provides the results. The results confirm our previous results (using VADER) that the sentiments extracted using the financial context dictionary do not exhibit any significant correlation with the stock market indicators. But the sectorial index of NIFTY Financial Services exhibits a small but significant correlation with the public sentiments expressed on Twitter.

Table 7. Kendall correlation coefficients. ${ }^{\star}$ represents the statistical significance at $5 \%$ level

\begin{tabular}{|l|c|c|}
\hline \multicolumn{1}{|c|}{ Index } & Ret & Range_v \\
\hline NIFTY Auto & 0.119 & 0.065 \\
\hline NIFTY Bank & -0.084 & 0.119 \\
\hline NIFTY FMCG & -0.067 & -0.012 \\
\hline NIFTY Financial Services & $-0.133^{\star}$ & 0.041 \\
\hline NIFTY IT & 0.072 & -0.050 \\
\hline NIFTY Media & -0.066 & -0.093 \\
\hline NIFTY Metal & -0.019 & 0.068 \\
\hline NIFTY Pharma & -0.092 & 0.129 \\
\hline NIFTY PSU Bank & -0.075 & 0.108 \\
\hline NIFTY Private Bank & -0.058 & 0.032 \\
\hline NIFTY Realty & -0.021 & 0.065 \\
\hline NIFTY 50 & -0.081 & 0.008 \\
\hline
\end{tabular}

\section{Discussion}

The present paper investigates in detail how the Twitter information influences the performance of the equity markets of a developing economy, with the evidences from Indian stock markets. VADER sentiment Analyzer has been used to extract the optimistic and the pessimistic public sentiments from the Twitter data.

The findings of this paper reveal that the impact of the Twitter information on the performance of the broad indices of the Indian equity markets is not significant. The robustness of the results has been confirmed by using another algorithm (Loughran \& Mcdonald, 2011) for the sentiment analysis. This suggests that the results are indifferent towards the use of different sentiment analysis techniques and there exists no significant correlation between the Twitter sentiments and the broad market indices (Nifty 50) of the Indian stock markets. This might be attributed to the fact that in the developing countries, the use of Information and Communication Technologies, especially the social media platforms is still in the emerging state as compared to the developed countries (Ilavarasan et al., 2018). Some of the reasons attributed to it are the affordability of devices, differential penetration rates, regulatory framework, etc.

This paper also explores the influence of Twitter information on the various economic sectorial indices of the Indian economy. The results show that the sectorial indices related to 
the bank and financial sector (NIFTY Private Bank, NIFTY Financial services, and NIFTY Bank) show a small but significant relationship with the Twitter information. A small but significant correlation between the NIFTY Financial services and the Twitter sentiments is also confirmed using the financial context lexicon (Loughran \& Mcdonald, 2011). The Granger causality tests also reveal the bi-directional causality between the returns from these sectorial indices and the positive and negative sentiments on the Twitter. The impulse response function indicates that the influence of the negative information on the stock market returns, persists for a longer period as compared to the influence of the positive information. The results obtained are interesting since only Banking and financial industry stocks have a significant relationship with Twitter sentiment, unlike other markets where all sectors are influenced by social networks' sentiment. The emerging economies offer attractive markets to the businesses in the developed economies, but they are still in the developing stage. The business strategies that work in the developed countries (such as using social media for information dissemination) might not be as successful in the developing countries (Ilavarasan et al., 2018).

This study provides answers to the research question raised in this study. The correlation coefficients in Table 2 and Table 3 clearly show that the Twitter information has no significant influence on the NIFTY50. However, the Metals and the Private Banks sectors' returns are found to be significantly correlated to the negative sentiments derived from the Twitter information. Similarly, the results from the granger causalty tests suggest that the positive and negative public opinions on Twitter can cause the returns of the sectorial indices NIFTY Bank, NIFTY Financial Services, and the NIFTY Private Bank only. Hence we fail to accept the hypotheses $\mathrm{H}_{4}, \mathrm{H}_{6}, \mathrm{H}_{12}, \mathrm{H}_{16}, \mathrm{H}_{18}, \mathrm{H}_{22}$, and $\mathrm{H}_{24}$. On the basis of these results, the answer to the research question would be that the Twitter information influences Indian stock market to some degree and the impact of positive and negative sentiments differs in lag as well as the particular indexes it influences.

Since the results from the Banking and Financial services sector show that there exists a significant relationship between the social media information and their stock market performance, indices related to these sectors are analyzed further for quantifying such effects. Therefore IRFs have been used for further analysis. The results depicted by the IRFs answer the research question raised by the hypothesis $\mathrm{H}_{3}$ in detail. It is clearly suggested (as shown in the Figure 1 to Figure 6) that in the sectors NIFTY Private Bank and NIFTY Bank, the influence of the pessimistic sentiments on the stock market performance lingers for a longer period of time as compared to the influence of the optimistic sentiments. So, the paper is interesting because of its results and also because it is the first paper that analyses the impact of Twitter on the various economic sectors of Indian markets. This study also provides further evidences to suggest that the rate of adoption of social media information is different for different economic sectors.

\section{Research implications}

This research has both practical and theoretical implications. Most of the research that investigates the association between the Internet information and stock markets is concentrated 
on the developed countries (Agarwal et al., 2019). This may be attributed to the fact that the developing economies pose an entirely different set of challenges e.g. stock markets of the emerging economies are not fully developed (Claessens \& Yurtoglu, 2013). This study shows that the Indian stock markets are not efficient with regards to the information available on twitter. It shows that the information on the internet does not get automatically reflected in the stock prices. Some possible reasons for this might be that the accessibility/affordability of the devices is still an issue. It also shows that the informational efficiency with respect to the information over the social media, is quite different for the different economic sectors. It also provides information as to how the positive and negative information impacts the various sectors of a country.

This study also has some managerial implications. The business managers can focus on specialized media channels to reach out to various stakeholders as the mass communication channels (popular social media) do not seem to have any significant influence on the broad market indices. This paper also suggests that the social media adoption rate for NIFTY Private Bank and NIFTY Bank is higher than other sectors. Therefore, the business managers or the social media mangers might consider using Twitter to disseminate more positive information and limit the negative content to build a positive image and thus use Twitter as an effective channel to reach out to their potential investors in two sectors (NIFTY Private Bank and NIFTY Bank).

\section{Conclusions}

The paper concludes that the Twitter information has an exceedingly small but significant relationship with the stock market performance of the sectorial indices related to the Banking and Financial services, in the developing countries. This also reveals that the social media can be used as an effective tool for disseminating useful information to the investors in these sectors. These new mass media channels might also be considered for retail marketing and relationship building with the retail customers. However, this relationship is not present in the other economic sectors as well as the over market index (Nifty50). This study emphasizes a need to investigate and collect concrete evidences to understand the reasons behind this. The results indicate that the negative twitter content has a long-lasting effect on the stock markets than the positive content. This suggests that the social media managers should carefully monitor their social media content for any negative content. Also, future research should focus on examining the reasons for the insignificant correlation between the overall performance of the market and the social media content through a detailed analysis of the trading behavior of the retail investors in the developing countries. The behavioral aspects of using social media information by the investors still need to be explored. Future studies can also explore whether there is any inclination towards the country-specific information channels on the internet. For this, the financial markets of the other developing countries and the information available on their homegrown social media platforms can be studied.

The findings of this research have a few limitations too. Firstly, it is limited to the study of the Indian stock markets. The stock markets of the other emerging economies might also be explored. Secondly, it only explores the subject through a macro level study and a detailed 
study at the micro level might help to understand the behavior of the stock markets of the emerging economies in light of the information available on the social media. Finally, this study is limited to the information available on the Twitter while other media channels could also be explored in future studies.

Further research could attempt to enlighten us on the underlying reasons to understand why the stock markets of the emerging economies behave differently from the stock markets of the developed countries. A study gathering the viewpoints of the investors regarding the information available through the social media might also help in furthering the knowledge in this field. Future studies can also explore whether there is a preference for the homegrown social media platforms over the globally popular social media platforms among the investors. This study focuses only on the equity markets, while other financial markets such as derivatives markets can also be included in further studies. A study comprising of a comparison of the influence of information from different social media platforms on different financial markets can be done in future research.

\section{Author contributions}

SA was responsible for the conception, design, development, interpretation and writing this study. SK and UG supervised the whole process.

\section{Disclosure statement}

No competing financial, professional, or personal interests from other parties.

\section{References}

Agarwal, S., Kumar, S., \& Goel, U. (2019). Stock market response to information diffusion through internet sources: A literature review. International Journal of Information Management, 45, 118-131. https://doi.org/10.1016/j.ijinfomgt.2018.11.002

Ahmed, R. R., Vveinhardt, J., \& Streimikiene, D. (2017). Interactive digital media and impact of customer attitude and technology on brand awareness: Evidence from the South Asian countries. Journal of Business Economics and Management, 18(6), 1115-1134. https://doi.org/10.3846/16111699.2017.1400460

Antweiler, W., \& Frank, M. Z. (2004). Is all that talk just noise? The information content of Internet stock message boards. Journal of Finance, 59(3), 1259-1294. https://doi.org/10.1111/j.1540-6261.2004.00662.x

Bag, S., Tiwari, M. K., \& Chan, F. T. S. (2019). Predicting the consumer's purchase intention of durable goods: An attribute-level analysis. Journal of Business Research, 94, 408-419. https://doi.org/10.1016/j.jbusres.2017.11.031

Bhardwaj, A., Narayan, Y., Vanraj, Pawan, \& Dutta, M. (2015). Sentiment analysis for Indian stock market prediction using Sensex and Nifty. Procedia Computer Science, 70, 85-91. https://doi.org/10.1016/J.PROCS.2015.10.043

Bollen, J., Mao, H., \& Zeng, X. (2011). Twitter mood predicts the stock market. Journal of Computational Science, 2(1), 1-8. https://doi.org/10.1016/j.jocs.2010.12.007

Chang, C. H., \& Lin, S. J. (2015). The effects of national culture and behavioral pitfalls on investors' decision-making: Herding behavior in international stock markets. International Review of Economics and Finance, 37, 380-392. https://doi.org/10.1016/j.iref.2014.12.010 
Chaturvedi, A. (2017). How India emerged as Twitter's fastest growing market in terms of daily active users. In The Economic Times. https://economictimes.indiatimes.com/opinion/interviews/indiabecame-our-number-one-market-in-daily-users-twitters-new-india-director-taranjeet-singh/articleshow/58601906.cms

Chui, A. C. W., Titman, S., \& Wei, K. C. J. (2010). Individualism and momentum around the world. Journal of Finance, 65(1), 361-392. https://doi.org/10.1111/j.1540-6261.2009.01532.x

Claessens, S., \& Yurtoglu, B. B. (2013). Corporate governance in emerging markets: A survey. Emerging Markets Review, 15, 1-33. https://doi.org/10.1016/j.ememar.2012.03.002

Clement, J. (2019, November 21). Global social media ranking 2019 | Statista. Statista. https://www.statista.com/statistics/272014/global-social-networks-ranked-by-number-of-users/

Culnan, M. J., McHugh, P. J., \& Zubillaga, J. I. (2010). How large U.S. companies can use Twitter and other social media to gain business value. MIS Quarterly Executive, 9(4), 243-259. https://pdfs.semanticscholar.org/a59f/46c2ee905fabc79885189c1c6781def6e45b.pdf

Deng, S., Huang, Z., Sinha, A. P., \& Zhao, H. (2018). The interaction between microblog sentiment and stock returns: An empirical examination. MIS Quarterly: Management Information Systems, 42(3), 895-918. https://doi.org/10.25300/MISQ/2018/14268

Díaz-Mendoza, A. C., \& Pardo, A. (2019). Holidays, weekends and range-based volatility. North American Journal of Economics and Finance, 52, 101124. https://doi.org/10.1016/j.najef.2019.101124

Enders, W., \& Granger, C. W. J. (1998). Unit-root tests and asymmetric adjustment with an example using the term structure of interest rates. Journal of Business \& Economic Statistics, 16(3), 304. https://doi.org/10.2307/1392506

ETMarkets.com. (2020). SGX Nifty share price: SGX Nifty futures recover on Trump's tweet, still down 100 points. The Economic Times. https://economictimes.indiatimes.com/markets/stocks/news/bigplunge-in-sgx-nifty-futures-signals-bloodbath-ahead-on-d-street/articleshow/73147846.cms

Fama, E. F. (1965). The behavior of stock-market prices. The Journal of Business, 38(1), 34-105. https://doi.org/10.1086/294743

Fan, R., Talavera, O., \& Tran, V. (2020a). Social media bots and stock markets. European Financial Management, 26(3), 753-777. https://doi.org/10.1111/eufm.12245

Fan, R., Talavera, O., \& Tran, V. (2020b). Social media, political uncertainty, and stock markets. Review of Quantitative Finance and Accounting, 55(3), 1137-1153.

https://doi.org/10.1007/s11156-020-00870-4

Feldman, R., Govindaraj, S., Livnat, J., \& Segal, B. (2010). Management's tone change, post earnings announcement drift and accruals. Review of Accounting Studies, 15(4), 915-953. https://doi.org/10.1007/s11142-009-9111-x

Garman, M. B., \& Klass, M. J. (2002). On the estimation of security price volatilities from historical data. The Journal of Business, 53(1), 67-78. https://doi.org/10.1086/296072

George, P. (2020, January 9). Nifty, Sensex end higher as U.S.-Iran tensions ebb. Thomson Reuters. https://in.reuters.com/article/india-stocks/nifty-sensex-end-higher-as-u-s-iran-tensions-ebb-idINKBN1Z80FB

Gonzalez, R. (2018). Facebook's new data restrictions will handcuff even honest researchers. WIRED. https://www.wired.com/story/fb-data-restrictions-hobble-researchers?mbid=nl_032318_daily_ list3_p2\&CNDID=48046051

Hansson, B., \& Hördahl, P. (2005). Forecasting variance using stochastic volatility and GARCH. European Journal of Finance, 11(1), 33-57. https://doi.org/10.1080/1351847021000025803

Hart, K. L., Perlis, R. H., \& McCoy, T. H. (2020). What do patients learn about psychotropic medications on the web? A natural language processing study. Journal of Affective Disorders, 260, 366-371. https://doi.org/10.1016/j.jad.2019.09.043 
He, W., Guo, L., Shen, J., \& Akula, V. (2016). Social media-based forecasting: A case study of Tweets and stock prices in the financial services industry. Journal of Organizational and End User Computing, 28(2), 74-91. https://doi.org/10.4018/joeuc.2016040105

Hutto, C. J., \& Gilbert, E. (2014). VADER: A parsimonious rule-based model for sentiment analysis of social media text. Proceedings of the $8^{\text {th }}$ International Conference on Weblogs and Social Media, ICWSM 2014 (pp. 216-225). https://www.aaai.org/ocs/index.php/ICWSM/ICWSM14/paper/viewPaper/8109

Ilavarasan, V., Kar, A., \& Gupta, M. P. (2018). Social media and business practices in emerging markets: still unexplored. Journal of Advances in Management Research, 15(2), 110-114. https://doi.org/10.1108/jamr-05-2018-111

Kapoor, K. K., Tamilmani, K., Rana, N. P., Patil, P., Dwivedi, Y. K., \& Nerur, S. (2017). Advances in social media research: Past, present and future. Information Systems Frontiers 2017, 20(3), 531-558. https://doi.org/10.1007/S10796-017-9810-Y

Kaushik, B., Hemani, H., \& Ilavarasan, P. V. (2017). Social media usage vs. stock prices: An analysis of Indian firms. Procedia Computer Science, 122, 323-330. https://doi.org/10.1016/j.procs.2017.11.376

Kim, J., \& Choi, H. (2019). Value co-creation through social media: A case study of a start-up company. Journal of Business Economics and Management, 20(1), 1-19. https://doi.org/10.3846/jbem.2019.6262

Kim, S. H., \& Kim, D. (2014). Investor sentiment from internet message postings and the predictability of stock returns. Journal of Economic Behavior and Organization, 107(B), 708-729. https://doi.org/10.1016/j.jebo.2014.04.015

Klepek, M., \& Starzyczná, H. (2018). Marketing communication model for social networks. Journal of Business Economics and Management, 19(3), 500-520. https://doi.org/10.3846/jbem.2018.6582

Kumaresh, N., Bonta, V., \& Janardhan, N. (2019). A comprehensive study on lexicon based approaches for sentiment analysis. Asian Journal of Computer Science and Technology, 8(S2), 1-6. https://doi.org/10.51983/ajcst-2019.8.S2.2037

Lahey, M. (2016). Everyday life as a text. SAGE Open, 6(1), 2158244016633738. https://doi.org/10.1177/2158244016633738

Leitch, D., \& Sherif, M. (2017). Twitter mood, CEO succession announcements and stock returns. Journal of Computational Science, 21, 1-10. https://doi.org/10.1016/J.JOCS.2017.04.002

Li, X., Xie, H., Chen, L., Wang, J., \& Deng, X. (2014). News impact on stock price return via sentiment analysis. Knowledge-Based Systems, 69(1), 14-23. https://doi.org/10.1016/j.knosys.2014.04.022

Liu, B., \& McConnell, J. J. (2013). The role of the media in corporate governance: Do the media influence managers' capital allocation decisions? Journal of Financial Economics, 110(1), 1-17. https://doi.org/10.1016/j.jfineco.2013.06.003

Liu, L., Wu, J., Li, P., \& Li, Q. (2015). A social-media-based approach to predicting stock comovement. Expert Systems with Applications, 42(8), 3893-3901. https://doi.org/10.1016/j.eswa.2014.12.049

Loughran, T., \& Mcdonald, B. (2011). When is a liability not a liability? Textual analysis, dictionaries, and 10-Ks. Journal of Finance, 66(1), 35-65. https://doi.org/10.1111/j.1540-6261.2010.01625.x

Malkiel, B. G., \& Fama, E. F. (1970). Efficient capital markets: A review of theory and empirical work. The Journal of Finance, 25(2), 383-417. https://doi.org/10.1111/j.1540-6261.1970.tb00518.x

Mobarek, A., \& Fiorante, A. (2014). The prospects of BRIC countries: Testing weak-form market efficiency. Research in International Business and Finance, 30(1), 217-232. https://doi.org/10.1016/j.ribaf.2013.06.004

Mohan, R., \& Kar, A. K. (2017). Demonetization and its impact on the Indian economy - Insights from social media analytics. In Lecture Notes in Computer Science: Vol. 10595. Digital nations - Smart cities, innovation, and sustainability (pp. 363-374). Springer, Cham. https://doi.org/10.1007/978-3-319-68557-1_32 
National Stock Exchange. (2019). National stock exchange of India Ltd. NSE. https://www.nseindia.com/ global/content/about_us/about_us.htm

Nayak, A., Manohara Pai, M. M., \& Pai, R. M. (2016). Prediction models for Indian stock market. Procedia - Procedia Computer Science, 89, 441-449. https://doi.org/10.1016/j.procs.2016.06.096

Oliveira, N., Cortez, P., \& Areal, N. (2016). Stock market sentiment lexicon acquisition using microblogging data and statistical measures. Decision Support Systems, 85, 62-73.

https://doi.org/10.1016/j.dss.2016.02.013

Phua, J., Jin, S. V., \& Kim, J. J. (2017). Gratifications of using Facebook, Twitter, Instagram, or Snapchat to follow brands: The moderating effect of social comparison, trust, tie strength, and network homophily on brand identification, brand engagement, brand commitment, and membership intention. Telematics and Informatics, 34(1), 412-424. https://doi.org/10.1016/j.tele.2016.06.004

Rimkuniene, D., \& Zinkeviciute, V. (2014). Social media in communication of temporary organisations: Role, needs, strategic perspective. Journal of Business Economics and Management, 15(5), 899-914. https://doi.org/10.3846/16111699.2014.938360

Risius, M., Akolk, F., \& Beck, R. (2015). Differential emotions and the stock market - The case of company-specific trading. In Twenty-Third European Conference on Information Systems (ECIS). Münster, Germany (pp. 1-17). https://core.ac.uk/download/pdf/50528565.pdf

Securities and Exchange Board of India. (2018, March 16). Order in the matter of Mr. Anirudh Sethi. SEBI. https://www.sebi.gov.in/enforcement/orders/mar-2018/order-in-the-matter-of-mr-anirudhsethi_38263.html

Selyukh, A. (2013, April 23). Hackers send fake market-moving AP tweet on White House explosions. REUTERS. https://www.reuters.com/article/net-us-usa-whitehouse-ap/hackers-send-fake-marketmoving-ap-tweet-on-white-house-explosions-idUSBRE93M12Y20130423

Siganos, A., Vagenas-Nanos, E., \& Verwijmeren, P. (2014). Facebook's daily sentiment and international stock markets. Journal of Economic Behavior and Organization, 107(B), 730-743. https://doi.org/10.1016/j.jebo.2014.06.004

Sprenger, T. O., Sandner, P. G., Tumasjan, A., \& Welpe, I. M. (2014). News or noise? Using Twitter to identify and understand company-specific news flow. Journal of Business Finance \& Accounting, 41(7-8), 791-830. https://doi.org/10.1111/jbfa.12086

Tetlock, P. C. (2007). Giving content to investor sentiment: The role of media in the stock market. Journal of Finance, 62(3), 1139-1168. https://doi.org/10.1111/j.1540-6261.2007.01232.x

Trusov, M., Bucklin, R. E., \& Pauwels, K. H. (2008). Effects of word-of-mouth versus traditional marketing: Findings from an internet social networking site. SSRN, 73(5), 90-102.

https://doi.org/10.2139/ssrn.1129351

van Dieijen, M., Borah, A., Tellis, G. J., \& Franses, P. H. (2020). Big data analysis of volatility spillovers of brands across social media and stock markets. Industrial Marketing Management, 88, 465-484. https://doi.org/10.1016/j.indmarman.2018.12.006

You, W., Guo, Y., \& Peng, C. (2017). Twitter's daily happiness sentiment and the predictability of stock returns. Finance Research Letters, 23, 58-64. https://doi.org/10.1016/j.frl.2017.07.018

Zhang, W., Li, X., Shen, D., \& Teglio, A. (2016). Daily happiness and stock returns: Some international evidence. Physica A: Statistical Mechanics and Its Applications, 460, 201-209. https://doi.org/10.1016/j.physa.2016.05.026

Zhang, Z., Zhang, Y., Shen, D., \& Zhang, W. (2018). The cross-correlations between online sentiment proxies: Evidence from Google Trends and Twitter. Physica A: Statistical Mechanics and Its Applications, 508, 67-75. https://doi.org/10.1016/j.physa.2018.05.051

Zheludev, I., Smith, R., \& Aste, T. (2014). When can social media lead financial markets? Scientific Reports, 4(1), 1-12. https://doi.org/10.1038/srep04213 